This item was submitted to Loughborough's Research Repository by the author.

Items in Figshare are protected by copyright, with all rights reserved, unless otherwise indicated.

\title{
What works in coach learning, how, and for whom? A grounded process of soccer coaches' professional learning
}

\section{PLEASE CITE THE PUBLISHED VERSION}

http://dx.doi.org/10.1080/2159676X.2017.1283358

\section{PUBLISHER}

(C) Taylor and Francis

\section{VERSION}

AM (Accepted Manuscript)

\section{PUBLISHER STATEMENT}

This work is made available according to the conditions of the Creative Commons Attribution-NonCommercialNoDerivatives 4.0 International (CC BY-NC-ND 4.0) licence. Full details of this licence are available at: https://creativecommons.org/licenses/by-nc-nd/4.0/

\section{LICENCE}

CC BY-NC-ND 4.0

\section{REPOSITORY RECORD}

Stodter, Anna, and Christopher Cushion. 2017. "What Works in Coach Learning, How, and for Whom? A Grounded Process of Soccer Coaches' Professional Learning”. Loughborough University. https://hdl.handle.net/2134/24366. 


\section{Abstract}

Research into sport coaches' learning previously relied on descriptive learning histories and retrospective coach perceptions that revealed little detail about the processes and outcomes involved. More recent nuanced approaches have started to evidence the idea that coaches actively integrate multiple experiences as interconnected modes of learning, influenced by preexisting biography (Abraham et al. 2006). A learning theory specific to coaching that can explain how practitioners dynamically interact with learning environments is a necessary addition to advance understanding, inform professional development opportunities and move the field forward (Cushion and Nelson 2013). This research aimed to address this gap by investigating the learning of 25 English youth soccer coaches. Longitudinal semi-structured interviews and video stimulated recall interviews were used to elicit knowledge use in practice, associated sources of learning, and moderating factors. Data were organised and analysed using techniques and principles of grounded theory (Strauss and Corbin 1998). A substantive grounded theory is presented to explain the filter process whereby individuals adopted, adapted and rejected elements of their experiences, leading to uneven learning in apparently similar situations. The findings suggest that coaches actively constructed and experimented with knowledge for use in socially situated coaching practice, through double-loop individual and contextual level filters, and 'reflective conversations'. In response to McCullick et al.'s (2009) calls, questions of 'what works', how and for whom in this context of coach learning are addressed for the first time. Elucidation of these processes can enhance professional learning and practice through advancing evidence based 'theory in context' (Kennedy 2014).

Keywords: sport coaching, learning, grounded theory, professional development, coach education 


\section{Introduction}

Understanding the learning and professional development of sport coaches is a relatively young yet growing area of scholarship. Major initiatives around the world as well as significant investment and resources have been targeted towards professionalising sport coaching, with the key strategy being the development of an appropriately educated, accredited and skilled workforce (Duffy et al. 2011, Taylor and Garratt 2010, Trudel et al. 2010) - and with it what Trudel et al. (2010) argue as a heightened level of accountability. While often conceived of as an educational endeavour (e.g. Jones 2006) sport coaching has only recently started to take influence from broader educational perspectives and learning theory (c.f. Nelson et al. 2006). For example, the idea that a profession should be built upon the foundations of effective education and continuing professional development (CPD) (Armour 2010), has guided coach licencing pathways. However, there remains limited critical engagement with learning theory (Cushion and Nelson 2013) alongside an escalating body of exceedingly context-specific literature which requires development to usefully inform the development of coaches.

Coaching has tended to uncritically recycle learning theories from other domains and present idealistic representations and prescriptions for practice, for example situated learning, communities of practice, and problem-based learning (Cushion and Nelson 2013). However, with a lack of direct research evidence the processes and outcomes involved in coaches' learning remain unclear. Indeed, research across a number of professional fields - including sport coaching - has failed to find conclusive evidence about the relative effectiveness of different types of CPD on participant learning and changes to practice (Griffiths et al. 2016, Neimeyer et al. 2012). As a result, Griffiths et al. (2016) argue that there is little secure evidence about 'what works' in CPD to change learners' behaviours and improve practice. Instead, there are a multitude of prescriptions for how coaches should effectively be developed 
that acknowledge the importance of the complexity of learning (e.g. Cushion et al. 2003) and the nature of the coaching process itself (Jones, 2006) but are "substantively and strategically incomplete because they lack data and evidence about practice" (McLaughlin and Zarrow 2001, p. 99, italics in original). A review of the CPD literature across education, physical education and sport coaching suggests that a focus on participants' learning in terms of receiving, building, and applying professional knowledge within a particular context is important (Armour et al. 2015, Nelson et al. 2013), as is the agency between the individual and specific CPD activities (Chesterfield et al. 2010, Opfer and Pedder 2011). However, the learning picture remains incomplete unless attention is widened to also examine key meso (e.g. at an institutional/club level) and macro structures (e.g. at a systems/organisational level), and how these mediate learning impact (Griffiths et al. 2016).

Coaching and learning to coach, like teaching can be viewed as involving a myriad of dynamic contextual and political variations, tensions, negotiations, and social dilemmas, making it a highly situation specific endeavour (e.g. Saury and Durand 1998, Jones et al. 2014, Thompson et al. 2013) that requires a context or coaching-specific 'coach learning' theory (Cushion and Nelson 2013). The starting place for such unique conceptual development and understanding needs to be grounded in practice and empirically supported. The need for models derived from empirical data to guide practitioners has been emphasised with a handful of novel grounded theories showing that coaching practice and coaches are a fertile source of information that offer rich insights for wider coaching practice (e.g. Côté et al. 1995, Gilbert and Trudel 2001, Groom et al. 2011). In teacher CPD, reviews also indicate a use of groundup empirical investigation to describe and model processes of change in teachers' practice, that expose previously unexploited understanding of the complex mechanisms involved (Avalos 2011, Clarke and Hollingsworth 2002). Indeed, the value and need for more evidence-based 'theories in context' that provide a more sophisticated, detailed and substantive understanding 
of 'what works' and the complexities involved in learning could more appropriately inform the professional development of sport coaches. In turn, this contributes to moving the coaching field forward, developing a more nuanced understanding of professional development and specific practice domains, as well as guiding practitioners and explaining impact on practice.

While scholarship in coaching has turned towards more established educational, social and political perspectives in attempts to move on from descriptive research and better understand the complexity of sport coaching processes (e.g. Jones 2006, Jones et al. 2014), in education a body of scholarly activity is dedicated to tracing the processes through which professional development achieves its various outcomes (e.g. Coldwell and Simkins 2011). Several years of interplay between theorising, application and adaptation has established frameworks that enable more nuanced engagement with key questions around whether and why long-term changes in knowledge and practice occur, and how educators' existing experiences, knowledge and contextual factors influence their learning (Guskey 2000, Coldwell and Simkins 2011). These include, for instance, important antecedents and situational moderating factors considered alongside various intermediate outcomes of educational interventions, with an emphasis on the complex interactions between these key variables (Coldwell and Simkins 2011). What is clear from the literature is that despite great enthusiasm for the value of CPD to facilitate practitioner growth, identifying the processes and mechanisms of 'effective' models remains elusive (Griffiths et al. 2016). As Armour et al (2015) have recently reported, CPD research in education has so far failed to identify the key to effective CPD, and as a result, 'despite decades of research, there remains little robust evidence to support definitive claims about what constitutes "effective" CPD' (p. 1). Griffiths et al (2016) argue that 'challenges faced in defining, developing and measuring "effective" CPD in sport coaching are part of much wider debates on this topic' (p. 4), with a focus on the 'dazzling complexity of the 
learning process', prioritising context, and innovatively bridging research/theory and practice likely to provide solutions (Armour et al. 2015, p. 1).

In addressing this, coach learning research is arguably lacking, as the work is typically characterised by a concern for defining, categorising and describing reported learning situations and experiences but conducting this retrospectively and devoid of context (Piggott 2013). The result is extensive but superficial and largely descriptive reports of coaches' professional learning perceptions and preferences occurring through a combination of several experiences such as formal education courses, workshops, reflecting on experience, working with mentors, observing and interacting with others, and self-directed use of resources (e.g. Erickson et al. 2008, Lemyre et al. 2007, Schempp et al. 2007, Stoszkowski and Collins 2015, Wright et al. 2007). This cross-sectional life history and survey based research offers little about the why or how of the idiosyncrasies arising from such a complex blend of learning seen to differ between individuals; while one practitioner may emphasise certain learning situations as key, another may value and make use of quite different situations (Werthner and Trudel 2009).

Furthermore, apparently similar situations appear to result in disparate learning for the individual coaches involved (Leduc et al. 2012, Stodter and Cushion 2014). This phenomenon has been explained with reference to the network of past experiences, knowledge, beliefs and dispositions that adults bring to every learning situation (Griffiths and Armour, 2013). Each coach's unique biography is thought to act as a filter or lens through which he or she views and interprets new knowledge, exerting a guiding influence on what is learned (Cushion et al. 2003, Trudel et al. 2013). Only recently though has research begun to provide evidence for this process and draw links between empirical data and explanatory models of learning (e.g. Leduc et al. 2012). For example, coaches interviewed after a shared educational programme reported validating, changing or intending to change their coaching practice, depending on their pre- 
existing biography (Leduc et al. 2012). Coaches that reported changing their practice were thought to have cognitively, emotively and practically transformed their biography, linking new learning to previous cognitive structures to re-establish accordance with the situation. Those who did not change either lacked the confidence to engage in the 'disjunctive' experience whereby new material did not match up with their previous biography, or simply perceived no gap between their original practice and the material on the course (Leduc et al. 2012).

Despite the emphasis on learning as (re)constructing individuals' existing knowledge, experiences and beliefs to change the whole person, learning from this perspective (e.g. Leduc et al. 2012) remains an entirely individual and cognitive process with the learner divorced from others, social interaction, cultural context and practice. In contemporary professional learning literature, socio-cultural theories are used to conceptualise learning as an outcome of the social interactions of a particular cultural setting (Griffiths et al. 2016, Hager and Hodkinson 2009, Billett 2004). What practitioners do and how they learn what to do is an outcome of what Kemmis (2010) described as the cultural and social-political reconstructions of practice and actions (Griffiths et al. 2016) - social and organisational contexts are rich in context, culture and emotion that, in turn, act as powerful factors in effective learning (Griffiths et al. 2016, Wenger 1998, Billet 2004, Postholm 2012). A recent case-study acknowledged this complexity, indicating that contextual and cultural influences overruled coaches' personal knowledge, beliefs and practice in their selection and observed implementation of new coaching content, suggesting the operation of a 'double-loop' filter (Stodter and Cushion 2014). Participants simply rejected discordant ideas and reverted back to what they perceived had previously worked in their particular coaching contexts. Despite the valuable longitudinal exploration of the impact of learning on coaches' practice behaviours, details of how learning mechanisms operate still requires elucidation. 
The current investigation is positioned to build upon these shortcomings. Taking influence from educational and teacher professional development perspectives can initiate a step forward from the prevailing basic cross-sectional self-report research designs in coaching (Goodall et al. 2005), facilitating a more systematic and sophisticated approach to exploring the key mechanisms behind coaches' professional learning, and the relationships between them. The aim of this research, therefore, was to explore longitudinally the processes involved in sport coaches' professional learning in context, with the purpose of building a new and original theoretical framework to understand coach learning. The significance of the work lies in moving on from recycling increasingly diluted general learning theories and building an empirically grounded, substantive coach learning theory, linked to practice, to inform more powerful learning opportunities, improve learning, and enhance coaching. In so doing, this paper aims to establish an integrated, holistic and contextually relevant understanding of coaches' professional learning processes.

\section{Method}

\section{Participants}

Following submission to and approval by the university ethics committee as a low risk project, 25 youth soccer coaches $(\mathrm{M}$ age $=31.6$ years, 22 male and 3 female) were purposively selected to take part in the research at different levels of data collection (Patton 1990). The data collection related to a project evaluating the impact of coach education, therefore participants actively coaching at a level and context relevant to the particular formal course were recruited indirectly through the sport's National Governing Body. The sampling was theoretically driven, to ensure that the data, concepts and theory generated fitted the research questions and phenomena under study (Strauss and Corbin 1998). Participants were selected due to their particular characteristics of relevance to the research (Morse 1994); they were all undertaking 
regular coaching practice at least twice a week in season, with some $(\mathrm{N}=20)$ completing a period of formal education alongside this. The participants had knowledge and current experience of learning to coach, and a willingness to take part in the study. Participants had been coaching for an average of 8.5 years, and all had completed the United Kingdom Coaching Certificate Level 2 or above ${ }^{1}$. They worked with male and female athletes of ages ranging from 3 to 19 in a mixture of settings from youth academies, centres of excellence and colleges, to grassroots and community teams ${ }^{2}$. Participants are numbered $\mathrm{C} 1$ to $\mathrm{C} 25$ throughout.

\section{Procedure}

Different participants underwent increasingly detailed levels of data collection as outlined in Table 1, allowing the progressive build-up of in-depth, longitudinal data to mirror the temporal nature of learning and change (Clarke and Hollingsworth 2002, Goodall et al. 2005). Eight coaches (numbered $\mathrm{C} 1$ to $\mathrm{C} 8$ ) took part in one-off semi-structured interviews (total minutes of data $=269$ ), with a further eight (numbered C9 to C16) engaging on two occasions six months apart, to allow for meaningful learning (total minutes of data $=647$ ). Meanwhile, nine participants (numbered $\mathrm{C} 17$ to $\mathrm{C} 25$ ) underwent multiple practice-linked video stimulated recall (SR) interviews over the course of a year and a half (2 - 6 sessions per coach, total minutes of data $=1603$ ). This extensive introspective research procedure invited participants to recall, aided by video clips of their behaviour, their concurrent cognitive activity during that event (Lyle 2003). In the current study, both interview procedures focussed on coaches' learning experiences, cognitions and knowledge with questions such as 'in what ways has your coaching changed over time?' 'How did you learn to do this?' and 'have there been any significant people in your learning?' The advantage of the SR interview procedure was that participants' perceptions of learning were explicitly linked to their coaching practice in context, overcoming some of the limitations of previous coaching research as well as coaches' poor self-awareness of their own practice (Partington and Cushion 2011). Where participants completed more than 
one instance of data collection, this was arranged to fit around any formal education episodes in a pre-post design (see Table 1), enabling evaluation of the processes through which the 'intervention period' achieved change or knowledge development (Coldwell and Simkins 2011).

\section{[Table 1 near here]}

\section{Analysis}

Data were organised using the framework of grounded theory (Strauss and Corbin 1998), a methodology that allows the researcher to develop theory from the data. This approach was merited as beneficial when there is no pre-existing theory available for the particular population (Holt et al. 2012), i.e. coach learners. A 'Straussian' approach was adopted as a set of flexible analytical strategies, characterised by a pragmatic position that sits between post-positivism and constructivism (Weed 2009). The process involved examining semi-structured and stimulated recall interview transcripts together, moving from basic description to analysis at increasingly abstract levels, with a particular focus on contexts, conditions and consequences (Holt et al. 2012). A system of concepts representing the processes involved in coaches' learning and moderating factors, were produced by labelling raw data extracts and grouping them together with others sharing common characteristics. For example, raw data extracts which related to coaches' beliefs were highlighted within the transcripts and organised into related features of the concept, if they shared common characteristics. Each new extract was constantly compared with previous concepts, and any that suggested a different feature of coaches' beliefs from existing groupings were labelled as pertaining to a new concept. Analysis became more abstract through relating concepts to each other, creating linkages, categories and subcategories. This axial coding process involved linking concepts, subcategories and categories through statements and memos denoting how they connected, or 
did not connect to each other (Strauss and Corbin 1998). Finally, a larger theoretical scheme was created by integrating and refining categories and their linkages through various iterations of diagrams and member-checking (Holt et al. 2012). For example, one coach said 'If someone comes to me with an idea and I can see it working... I can get my head round that and think right well let's give that a go and see if it works', which was coded under the conditional concept 'seeing is believing', and linked to the consequence 'try out'. The proposed concepts and their connections were drawn out and shown to two of the participants (Groom et al. 2011) for feedback on whether they fitted into their learning process. Through an iterative process of constant comparison and adjustment, these linked concepts eventually formed part of the resulting grounded theory shown in Figure 1.

\section{Results and Discussion}

\section{[Figure 1 near here]}

\section{The 'Filter' Process}

Figure 1, an integration of the grounded theory concepts, represents in diagrammatical form the participant coaches' accounts of how they approached and learned from different experiences. Actions, conditions and consequences are shown in boxes, while arrows represent the links between these, depicting directional processes. Knowledge and practice, closely intertwined with beliefs about coaching and 'what works', are shown as framing the entire phenomenon, playing roles in all stages of the learning process. Two of the central elements within Figure 1 make up a double-loop filter process, illustrating processes identified in previous research (Stodter and Cushion 2014). The coach's knowledge, beliefs and practice at the individual level precede a secondary level contextual filter. The elements of any learning experience engaged in by the coach, therefore, passed through these two levels before new knowledge could be translated into practice and 'tried out', for potential full integration within 
the coach's biography. Thus new concepts moved through the process from beliefs and knowledge towards practice. In addition, reflective processes also had a role in the adaptation of constructed knowledge. Each aspect of the model will now be presented in turn (Figures 2, 3 and 4) with emphasis on the interactions and relationships between concepts in the interview data, and elaborated on using contextualised verbatim text examples ${ }^{3}$.

\section{Individual level filter}

The first aspect of the process is that coaches approached and understood learning experiences through the lens of their existing beliefs, knowledge and coaching practice; in other words, their biography acted as a continuous influence on their perspective (Cushion et al. 2003, Jarvis 2006, Leduc et al. 2012). Approaching any type of learning experience in its entirety, coaches perceived a number of different aspects or 'bits and pieces' $(\mathrm{C} 13,2)$ which passed through this cognitive filter to be either discarded or adopted (see Figure 2).

[Figure 2 near here]

The coach education course that the majority of participants attended, for example, fits into Nelson et al's (2006) conceptualisation as a formal learning situation. Nonetheless, coaches reported 'picking up ideas' $(\mathrm{C} 10,2)$ from a variety of occurrences ranging in formality within the course, including classroom sessions, tutor feedback, giving peer feedback, conversations, watching other coaches, and taking part in practical sessions as players. This speaks to the broader notion of lifelong learning that can better encompass self-directed and more incidental learning overlapping with CPD (Goodall et al. 2005). Wider learning experiences were broken down to focus on smaller elements; the various ideas or specifically 'chunks' of knowledge available in such experiences. This is equivalent to the idea of knowledge concepts set out by Entwistle et al (2000) and referred to in coaching by Abraham and colleagues (2006). Often encountered through formal education, concepts have a shared 
rather than personal meaning (Entwistle and Peterson 2004), characterised by specific procedural knowledge, and underpinned by associated declarative knowledge (Abraham et al. 2006). The current data demonstrated that an initial cognitive filter process took place at the individual level, with coaches reporting the identification of new knowledge concepts as matching, mismatching, or fitting in with their personal existing knowledge, beliefs and practice. As depicted in Figure 2, each of these alternatives had different consequences for actions further down the process chain, and therefore for subsequent implementation and behaviour.

\section{Matching concepts}

C2 explained how a coaching strategy advocated on a formal course matched his existing practice and preferences, leading to increased use of the method and reinforcement of practice:

It was coaching within the flow of the game, and that's very much what I do now. I very rarely stop it, but bringing them in and talking to them, I like that idea. I've done it before but not to the scale that this is asking you to do. Just reinforcing what I've been doing. When you work with the individual player rather than stopping everyone, I like to think I do that, but I shall make sure that I'll do a lot more of that, and it's just reinforcing more my work up to as yet. (C2)

When a certain 'bit' of knowledge from a learning situation had already been learnt by a coach, the concept closely matched that coach's existing cognitive structures and therefore served to confirm, reinforce and add 'a bit of weight to' $(\mathrm{C} 17,2)$ that area of knowledge, making it more readily available for use in practice. From a behaviourist point of view, reinforcement of certain practices led simply to outputs in the form of continued or increased use of such behaviours (Tusting and Barton 2003). Moon (2004) referred to this process as non-reflective learning or assimilation of congruent ideas to individuals' cognitive structures. Ideas are slotted 
together on the basis of relatively superficial similarity, without any meaningful cognitive processes or changes in understanding (Moon 2001).

\section{Mismatching concepts}

In contrast, certain ideas that did not match, and contradicted the coach's existing knowledge, practice and beliefs were 'filtered out' and quite swiftly rejected. For example, C20 described how he rejected formal course content without trying it in practice:

Well it's probably stuff that I didn't agree with. Which would probably be that's the stumbling block before instead of actually thinking, Oh I don't think it'll work but we'll give it a go. You do tend to stick to what you know $(\mathrm{C} 20,3)$.

This situation, whereby the new material of learning was in conflict with the learner's network of knowledge, experiences and beliefs, has been referred to as cognitive dissonance (Moon 2004) or disjuncture (Jarvis 2009) in the learning literature. While disjuncture is portrayed as a moment of potential for learning (Jarvis 2009), coaches in this study simply rejected discordant ideas and reverted back to what had previously worked to maintain accordance or harmony in their biography (Jarvis 2009). The process of picking out ideas that fit into beliefs and collecting evidence to confirm pre-existing knowledge, meanwhile rejecting concepts that are more challenging, has been labelled 'safe simulation' (Cushion 2013). This approach can enable practitioners to adopt seemingly novel aspects of learning experiences while preserving their underlying assumptions about coaching and norms of practice (Light and Robert 2010). In this way, the new material becomes fragmented and mutated, then transmitted along with traditional norms and folk pedagogies as a 'shared repertoire' (Piggott 2013), with innovative or new knowledge in danger of becoming washed out (Cushion et al. 2003). 


\section{Concepts that 'fit'.}

If the content of learning experiences did not either contradict or completely match coaches' existing knowledge, practice and beliefs, a third alternative was that some of the ideas were new to the coach yet fitted in with their biography. Participants reported that they liked, agreed with and 'picked up' $(\mathrm{C} 10,2)$ these particular concepts:

So you know, you watch all the coaching sessions, you pick the bits that you think work and you like, and you put them together in your own session and it just builds...Like the coach that I worked with last season I've mentioned, some of the ideas that he had really rubbed off on me and I put them in 'cause...you know, I like them. $(\mathrm{C} 20,1)$

On encountering any learning experience, therefore, coaches filtered different ideas, taking 'bits' of knowledge that fitted in to use in their coaching practice, reinforcing their existing knowledge and practice and rejecting contradictory concepts (Figure 2). Biography thereby acted as a frame of reference (Mezirow 2009) that had 'a guidance function' for the noticing and perception of new learning (Moon 2001, p. 69). Efforts to construct models of teacher development have similarly unveiled that despite the diversity of learners and learning, prior beliefs are a constant factor supporting or hindering change (Avalos 2011). Here, coaches made sense of structured, context-devoid concepts by looking for links, similarities and conflicts with their own previous experiences, resulting in personal and therefore variable understandings (Abraham et al. 2006, Entwisle and Peterson 2004).

\section{Contextual level filter}

Nevertheless, the data suggested that the learning process was not quite as straightforward as simply taking what fits and using it in practice. Coaches reported agreeing with certain aspects of learning experiences that fitted in with their biography, but not implementing this learning 
due to the context in which they were working. In this respect, contextual considerations acted as a second-level filter loop, over and above biography. Coaching context overruled any learning that fitted in with knowledge, beliefs and practice, as C22 describes:

I don't think it's a bad suggestion, but to say that you should do that with every group I think is unrealistic. I don't think it would work with this group, others have tried similar things and it's just not worked...But I could see it working with other groups quite easily, younger groups, the under $11 \mathrm{~s}$ for instance would probably take to that $(\mathrm{C} 22,4)$.

As shown in Figure 3, participants appeared to judge whether concepts would fit with their coaching context based on their understanding of the situation and associated belief that concepts were usable and would work or not. Abraham et al. (2006) explained this process as the internalisation of concepts, which become conceptions as they are applied to a particular context meaningful to the practitioner. A conception is generally organised around beliefs about how it is implemented in the field, therefore forming the basis of meaningful new knowledge in memory; idiosyncratic and applicable to the type of context it was learned in (Entwistle et al. 2000). When recognising a similar situation later on, the associated conceptions are likely to be brought to mind (Entwistle and Peterson 2004).

[Figure 3 near here]

\section{Rejection}

The coaches believed that new concepts were not usable in context informed by knowledge of context and specifically the players they were working with. Social relationships such as watching and working with other coaches were an important influence on coaches' beliefs in this respect. Based on this, in the example above $\mathrm{C} 22$ rejected the particular coaching method 
without trying it in practice, despite agreeing with the idea itself. Although this coaching strategy had passed through this coach's initial individual-level filter and had then been rejected at the contextual level, he remained open to using the strategy in a different context, suggesting the knowledge concept had fed back to become integrated into coaching knowledge, but not his current practice as a conception. Therefore the data suggests a clear and decisive distinction between knowledge and behaviour, with context a moderating factor on whether learning could bridge this gap.

\section{Adaptation}

Instead of rejecting content that they felt would not work in their specific coaching context, some coaches talked about adapting conceptions so that they would fit with "what works for your team, or your set of players' $(\mathrm{C} 23,3)$, 'dependant on again knowing the player and understanding how they learn' $(\mathrm{C} 1,6)$. Despite $\mathrm{C} 23$ 's assertion that she would 'either adjust that or do something that's worked in the past' this was by no means a straightforward deliberate decision, between rejection and adaptation. Instead, the data suggested a course of action resting on the individual's openness of mindset and reflection skills, as well as the nature of the content itself and existing knowledge of their work context, players and pedagogy:

I learnt just by, when you're in the game or watching the game and you're thinking, um I wonder if that could work with my Sunday afternoon group, probably not, but if I - so it was kind of learning through your thought process; not learning through necessarily the coaches, the tutors coaching you through it. But I think all the time when you're in those sessions, or watching those sessions you're constantly, well I was constantly thinking how would I use this in my group at the moment, or how could I adapt that, so you're trying to get ideas for your next sort of week's sessions if nothing else. I think 
there's some stuff that's just not relevant for some age groups, but other stuff you think, well it's not but it could be adapted so it could work. $(\mathrm{C} 9,2)$

At this contextual filter level (Figure 3), coaches' understanding of new conceptions was determined by their beliefs rather than knowledge of whether it does actually work; in the words of C18, 'I don't know because I've not tried it'. The 'reject or adapt' mechanism could also occur after the next, more practical stage in the learning process, which will be explored in further detail in the following section.

\section{'Seeing is believing'}

One way that knowledge could arrive immediately at the contextual level filter, bypassing individual biography, was if, in their interactions with others, coaches could see relevant material working or they could see the benefits of using the new knowledge:

I think if I can see - someone comes to me with an idea and I can see it working and it being relevant for the player and enjoyable, I can get my head round that and think right well let's give that a go and see if it works. $(\mathrm{C} 24,2)$

Convincing coaches of the beneficial outcomes of using knowledge, and that it is usable in their everyday context, was therefore one way to circumvent the filter's barriers to learning. In the words of one of Nelson et al's (2012) coaching practitioners, 'seeing is believing' (p. 7). The results corroborate the idea that individuals make sense of concepts according to their beliefs regarding how they can be used. This adds evidence to claims by Armour and Yelling (2004) and Guskey (2002) in educational CPD that 'significant change in teachers' attitudes and beliefs occurs primarily after they gain evidence of improvements in student learning' (p. $383)$. 


\section{From knowledge to practice}

Once coaches believed that the new knowledge would work in context, either as it is or with some adaptation, the next step in the process was to experiment with using it in practice. Here, coaches retained their focus on 'what works':

It's almost an experiment to see does it actually work if I coach this way? Does that work with the players, does it work with me, do I feel comfortable doing that? $(\mathrm{C} 22,4)$

Such engagement in authentic social practice to try out new conceptions follows Vygotsky's (1978) ideas. Coaches described this as experiential, trial and error learning, regardless of the original source of the ideas being tested. As indicated by C22's questioning of himself, reflection played a role in the judgement process. For many coaches, however, this was a much more tacit, uncritical process:

Trial and error, trust in myself, seeing what's worked and what hasn't worked, trust me a lot of it hasn't worked, but that's what experience is, experience is mistakes. I trust, I know if it feels right. I'm very much an instinctive coach, I know if it's not quite right or if I'm not getting through to the player, I just know. (C2)

This coach hints at using his existing tacit coaching knowledge, emphasising that his biography was inescapably bound up within the whole learning and filter process. Accurately mirroring the current data, Eraut (2000) explains how new codified knowledge concepts are applied for practical use in professional work. He asserts that the 'transfer' (p. 133) process involves 1) understanding the situation, which itself requires appropriate use of some prior knowledge; 2) recognising that the concept or idea is relevant; 3) changing it into a form appropriate for the situation, and 4) integrating that knowledge with other knowledge in the planning and implementation of action (Eraut 2000). With the addition of the 'try out' reflective loop in the current model, each particular conception became available for use in the same type 
of situation it was implemented in; its meaning for the knower embedded in a cluster of experiences of using it (Eraut 2000). The coach's mental model of the conception therefore includes typically tacit knowledge of how to use that conception in practical situations (Eraut 2000).

\section{Reflective feedback loop}

Judgements of 'what works', and consequent rejections or adaptations of knowledge conceptions, were based on a feedback loop process, illustrated in Figure 4. When coaches perceived that the new learning did not work in practice having tried it out, they progressed to either reject it or enter into a cycle of continuous adaptation and experimentation, remarkably similar to Schön's (1987) 'reflective conversation':

If it doesn't work, you know, evaluate and the next time you do it, you know, that didn't work so we'll try it a different way this time. If it did work, do the same, do the same way again. $(\mathrm{C} 21,3)$

[Figure 4 near here]

This repeating spiral, centred on active experimentation (Kolb 1984), was portrayed in coaching by Gilbert and Trudel (2001); showing experiential learning as developing and refining coaching strategies through a sub-loop of strategy generation, experimentation, then evaluation (Gilbert and Trudel 2001). Experimentation and evaluation consisted of a 'virtual world' or 'real-world' trial of a coaching strategy; equivalent to the 'will it work in context?' and 'try out - does it work?' stages in the present model. Both Gilbert and Trudel's (2001) and the current coaches described the feedback loop as 'just instinct' $(\mathrm{C} 21,3)$, displaying no overt, declarative decision making. In contrast to the typical idealistic and rational language of coach developers and CPD programmes (e.g. Armour et al. 2015), 'what works' in the coaches' 
minds was not linked to explicit outcomes or definitions of success for their athletes. Similar could be said of the coaches' own development; given the operation of this filtering process, learning was left aimless and subject to unacknowledged individual and contextual level variances, with outcomes disregarded. Yet, models of teachers' growth suggest this 'domain of consequence' is a key area where change (i.e. learning) can take place (Clarke and Hollingsworth 2002). Here, any adaptations to learned knowledge were tried out, then rejected or adapted several times over in a cycle mechanism. If the result was satisfactory to the coach, they adopted it as part of their 'tried and tested' practice repertoire for sustained use and integrated it into their coaching biography:

You kind of naturally take away the bits that work for you, and then you bring in some of your other coaching that you've perhaps learned before or you've learned along the way after the course. So I think it's kind of for me, a natural thing. $(\mathrm{C} 25,6)$

In this way, coaches were seen to constantly work through a cycle of constructing and linking new knowledge, which was tightly bound to context-specific practice, into their existing knowledge structures. In line with a constructivist perspective, learning is seen as 'holistic adaptation' (Kolb 1984, p. 31) to experiences in the social and physical world. Newly updated biography, in turn, worked as a filter for the next learning experience they engaged in, meaning that the coach's knowledge, beliefs and practice were in a constantly dynamic state of flux. The continuous process (rather than outcome) of learning (Kolb 1984) is therefore 'lifelong' as biography continues to alter, creating a constantly changing person (Jarvis 2009). The data therefore provides a notable contrast with techno-rational ideas of gaining particular competencies or outcomes of learning often seen in formal coach education or 'training' (Cushion and Nelson 2013). 


\section{Moderating factors}

The choice between rejecting and adapting conceptions, as part of the reflective feedback loop, was a significant feature of the learning process. Indeed, it is important to note that deliberate reflective practice did not necessarily ‘just happen' (Moon 2004). Rather than being aware of a clear choice between rejecting and adapting conceptions, coaches referred to their own personal openness, and contextual factors when discussing the process. C17, for instance, explained how he had developed new knowledge conceptions from other coaches through the filter process and trying things out, with his openness and the context determining whether he would adapt or reject and revert to previously learned knowledge and practices:

Just experience and all the coaches and watching different coaches, picking up things and then just trying it out to see if it works. Sometimes things work, sometimes they don't, but once you try it then you're sort of tweaking things here and there. Sort of if you don't try it you won't know. It's one of those, and that's one of the things I do quite a bit. Certainly this is my second season at the club. The first season I probably stuck more to - what would you say? Not basics but ... tried and tested stuff. $(\mathrm{C} 17,2)$

This develops Gilbert and Trudel's (2001) finding that coaches' selection of options was influenced by access to peers, stage of learning, issue characteristics and coaching environment; that is, the influence of parents and league administrators. In the current model, however, context was seen to encompass a broader range of social and environmental factors that once again took precedence over other moderators. In teaching too, it is well established that practitioners' thinking, action and growth is the result of an interplay between their life histories, classroom and school settings, and the broader social and political contexts in which they work; also termed the change environment (Clarke and Hollingsworth 2002, Day 2002). The current research intimates more detail on how this can happen. Schön's ideas on the impact of context are relevant for clarifying why some coaches simply rejected knowledge that was 
perceived not to work in practice, while others adapted conceptions for further experimentation. He stated that reflection is most likely to be found in an environment in which there is 'a high priority on flexible procedures, differentiated responses, qualitative appreciation of complex processes, and decentralized responsibility for judgement and action' (Schön 1983, p. 338). Teaching contexts (e.g. WestEd 2000), and the coaching contexts investigated in this study varied in terms of these characteristics and their influence on practitioners' learning. C19, for instance, was in charge of his own age-group of players, working at a youth academy where he could meet and discuss practice issues with other coaches, often coming up with new ideas and adapted sessions as a result. He explained how this environment enhanced his learning in the form of adopting a new strategy:

What I do all the time really is in the games get them to make formations and pick teams so they're actually engaged in the actual tactical side of it a bit more... So that was just a gradual thing that we developed through the club and just as coaches talking and discussing and reflecting really. $(\mathrm{C} 19,1)$

Participants were seen to collaborate with others in adapting their practice where context allowed, for example in the above situation and for C23 who 'after each session' would debrief with a colleague who 'might go yeah or no, you could maybe use that as an example to get them to do this, yeah, bouncing ideas off'. C25, in contrast, was afforded very little flexibility or responsibility for judgement and action in his club context, working within a wellestablished structure in a pressured climate of accountability for demonstrating 'correct' coaching:

You're always conscious of your own peers or other coaches who are around watching and thinking - are you giving the right information and are you doing it, are you going in right? Are you doing it right? And also you've got parents there, they've seen other 
coaches working with the players, they may have an opinion on you. You've got your superiors there who might have an opinion on what you're doing. Because this is a paid environment that you're in, there's also an added pressure on the coach to ensure that what he's doing is right. $(\mathrm{C} 25,2)$

Despite the presence of several other age-group coaches and an assistant, this environment did not support collaborative adaptation. Deterred from experimenting with different ideas outside the curriculum and the normative ways of doing coaching, C25 failed to change his coaching behaviour and practice, opting for 'safe simulation' (Cushion 2013). Since coaching is strongly associated with maximising performance success and winning, with coaches in some settings accountable for and dependent on achievement of such outcomes, it is perhaps understandable that they 'are reluctant to take risks or depart too far from the status quo of accepted practice' (Light and Robert 2010, p. 113). Coaches' reflective cycles of learning are bound up with coaching practice that often takes place in contexts subject to power relationships and deeply held anti-intellectual beliefs (Abraham et al. 2009; Thompson et al. 2013). Consequently, while learning situated in everyday practice is essential, coaching environments are not often conducive to generating new ideas, supporting active experimentation, or facilitating transfer from knowledge to implementation (Abraham et al. 2009, Light and Robert 2010).

These contextual variations combined with personal openness to impinge on coaches' reflective feedback cycles and overall quality of learning. Individual subscription to 'right' and 'wrong' ways of coaching underpinned by legitimate knowledge provided by authority, such as club bosses, follows a dualistic assumption about knowledge (Entwistle and Peterson 2004). Individuals holding these more absolute, closed ideas about knowledge tend to also approach learning as simple reproduction of the accepted norm (Entwistle and Peterson 2004, Piggott 2012). As learners begin to recognise knowledge as provisional and relative, evidence is used 
to reason among alternatives (Entwistle and Peterson 2004); in other words, experimenting with and critically evaluating new conceptions in practice based on 'what works'. Coach C22 provides an example of this openness:

I've got to find out somehow, I've got to try at some point, so why not now? Some people wouldn't want to, and some people would probably be scared to as well, because you do have to take a lot of criticism, with how you coach, for it. That'll be from people who don't understand or have set views on how football should be coached. $(\mathrm{C} 22,4)$

Abraham and colleagues (2009) compared such practitioners to chefs who use in-depth knowledge of ingredients to develop new ideas and orchestrate successful outcomes, as opposed to 'cooks' who live by other peoples' tried and tested recipes as safe simulators (Cushion 2013). In the field of educational evaluation, meanwhile, Eisner (1985) argued that the 'art' of education (or coaching) and its many complex processes can be knowledgeably appreciated through 'connoisseurship', a critical appreciation that illuminates a concept's qualities and allows an appraisal of its value, facilitating deeper understanding. Alongside an appreciation of the relative nature of coaching knowledge and growing 'connoisseurship', learning is said to become more reliant on individuals' efforts to fully understand ideas for themselves, by relating them to previous knowledge and experiences, thereby seeing things in

a different light (Entwistle and Peterson 2004). Thus the idea of meaningful, transformative learning (Mezirow 2009) rests on the open-minded transformation and implementation of conceptions in practice, through reflective linkage with existing knowledge (Moon 2001), as displayed in the current model.

\section{Summary and Conclusion}

This paper has presented the first substantive grounded theoretical framework of sport coaches' learning processes (Figure 1) and made explanatory links to other literature in coaching, 
learning and professional development. Although 'tidy maps of knowledge and learning are usually deceptive' (Eraut 2000, p. 133), the model represents an original and useful heuristic representation of the way this particular group of coaches actively constructed and adapted knowledge for use in socially situated coaching practice, through double-loop individual and contextual-level filters, and 'reflective conversations'. The research also attempts to link the micro factors of individual coach learning with the macro factors of context and contextual issues that enable or inhibit the learning process. While many of the ideas around the process of coach learning have been recognised for some time, the processes remain something of a 'black-box'. The key elements of the model therefore illustrate important processes of how concepts from learning experiences are rejected, adopted or fitted into coaches' evolving biography (Figure 2) with consideration to important contextual and moderating factors (Figure 3) as well as practical implementation (Figure 4). This provides detail to evidence and advance previous ideas that coaches 'cherry pick' certain elements of learning experiences (e.g. Cushion et al. 2003). This for the first time in research related to coach learning offers an explanation of why and how this occurs, as well as the subsequent impact on coaches' practice. A significant theme throughout, often a key driver in adult learning (Goodall et al. 2005, Knowles 1980) is the expressed pragmatic desire for relevant, practical knowledge that 'works' and leads to enhanced coaching ability (c.f. Nelson et al. 2012). The model also offers knowledge behind the powerful and pervasive notion of 'what works' for coaches and why this differs between individuals, relying on their biography and context, and therefore accounts for idiosyncratic learning that results from the apparently comparable learning situations coaches encounter.

Although these coaches and their contexts were all unique, they and their learning also shared enough commonalities with other coaches to ensure that we can learn from them (Armour and Yelling 2007). The discussion has highlighted the 'commonality' of several aspects of the process to other studies in coaching and learning, suggesting wider relevance to 
other practitioners in similar learning environments (Holt et al. 2010). A number of facets bear resemblance to Clarke and Hollingsworth's (2002) model of teacher professional growth, whereby reflection and enactment mediate change sequences in interconnected external, personal, practical and consequential domains. While both frameworks essentially follow cognitive approaches to learning, they touch upon principles from other more constructivistinformed theories in combination (e.g. Entwistle and Peterson 2004, Eraut 2000, Gilbert and Trudel 2001, Moon 2001, Schön 1987). Learning scholars such as Vygotsky (1978), Mezirow (2009), and Jarvis (2009) adopt a similar notion that learning is both an individual and a social process, and the complementarity of these two perspectives has been endorsed in the coaching and teaching literatures (e.g. Clarke and Hollingsworth 2002, Jones et al. 2014, Postholm 2012). The model therefore meets the suggestions of Colley (2003) and Cushion and Nelson (2013) in providing the basis of a specific 'coach learning' theory that draws on an eclectic mix of relevant explanatory frameworks. At the same time, it conforms to a coherent theory of learning (Clarke and Hollingsworth 2002) and there may be a broader theoretical contribution and practical relevance for educational perspectives in appreciating what is influential and effective for practitioner learning in related settings. For instance, the current findings suggest that viewing CPD as part of educators' wider learning in context is valuable in understanding its effectiveness, while the approach adopted could be useful for researchers aiming to counteract accusations that educational CPD literature is still under-theorised and unable to inform evidence based practice (e.g. Kennedy 2014). Indeed, this study can help to counteract the tendency to become too deeply entrenched in our own professional spheres; as Jones (2015, p. 159) recently identified, 'There is also much to be lost by failing to look outside the furrow at the ways in which other professionals, within or beyond our own areas of focus, engage in professional learning.' 
The results provide empirical evidence and therefore substantiates several discussionbased papers in recognising that coaches see and interpret new situations on the basis of their formative experiences, which continuously influence their perspectives, beliefs and behaviours (e.g. Abraham et al. 2006, Armour 2010, Cushion et al. 2003, Leduc et al. 2012, Schempp and Graber 1992, Werthner and Trudel 2009). It is not a novel concept that new ideas or learning experiences are negotiated and not simply accepted by educational practitioners, with their belief systems exerting huge value and power in constructing their practice (Chesterfield et al. 2010, Schempp and Graber 1992). Nevertheless, previous literature has treated the phenomenon at a simplistic level, without attempting to delve into the actions or mechanisms involved, or their links to situated practice (e.g., Trudel et al. 2010). In coaching, the key influence of others and the wider context has until now been largely neglected. Likewise, the design and provision of professional learning opportunities has consistently failed to accommodate this well-established process (Armour 2010, Chesterfield et al. 2010, Cushion et al. 2003).

Indeed, the current findings for the first time demonstrate the uneven and arguably flawed impact of 'generic' learning episodes, underlining why individualised, contextually and practically relevant learning opportunities are key for learning. The identified filter and reflective conversation processes were largely inadvertent, based on tacit understanding of how to implement concepts in context and implicit judgements of 'what works'. Coach developers could target these processes to enhance the impact of learning situations (Abraham and Collins 1998). For instance, the current study suggests that supporting learners to uncover and link their underlying reasoning, assumptions and values to disjunctive concepts, transforming them for integration into biography (Jarvis 2006) would facilitate meaningful learning. In particular, the findings intimate that challenging individuals' perceptions of what practice that 'works' looks like in context, deconstructing 'assumed know-how' (Chesterfield et al. 2010) and 
experimenting with implementation of new knowledge in settings open to innovation and failure could be particularly powerful.

Overall, professional development would do well to take such steps to avoid learners' rejection of information that could otherwise be highly valuable, challenging the status quo by pushing practitioners beyond their 'tried and tested' knowledge, and advancing the profession as a whole. At the very least, formal learning provision needs to begin to acknowledge the complexity of learning in its design and delivery, with a more sophisticated 'pedagogy of coaches' at its core. A natural progression from this study is to further develop, implement and test the presented model in different settings (Strauss and Corbin 1998), working towards a 'grand' theory of learning for wider use in professional development situations. The findings can also add a new dimension to long standing and ongoing efforts to construct a wider empirically-grounded 'theory in context' (e.g. Clarke and Hollingsworth 2002) of effective continuing professional development in education that can account for the many different forms of CPD provision and activity (Harland and Kinder 1997, Kennedy, 2014). Looking further ahead, there also is a need to follow the suggestions of CPD evaluation frameworks (e.g. Coldwell and Simkins 2011, Goodall et al. 2005) in addressing and linking to the ultimate outcomes of professional development; that is practitioner capacity, short and long term athlete or pupil outcomes, and shifts in the profession and culture of coaching.

\section{Notes}

1. The United Kingdom Coaching Certificate (UKCC) is a recognised professional framework for developing, endorsing and continuously improving governing body of sport coach education programmes, brought in by a government-commissioned Coaching Task Force. It is split into levels beginning at 1 and progressing up to 4 , providing a clear vocational pathway for coaches (Sports coach UK, 2015). 
2. Professional men's football clubs in England and Wales each have a centre for developing youth players, known as Academies or Centres of Excellence. Players are contracted to an Academy typically from the age of 9 and train part-time. At the age of 16 boys are offered full-time 'scholarships' that lead, for successful players, to full-time adult professional contracts (Cushion and Jones, 2012; The FA Premier League Ltd, 2011).

3. Throughout, the relevant interview number is referred to in brackets after the participant number 
Table 1. Outline of study design and participant involvement

\begin{tabular}{|c|c|c|c|}
\hline \multirow[b]{2}{*}{$\begin{array}{l}\text { Participant } \\
\text { numbers }\end{array}$} & \multicolumn{3}{|c|}{ Timeline } \\
\hline & Baseline & $\geq 6$ months & Follow up \\
\hline $\mathrm{C} 1$ & $\begin{array}{l}1 \text { semi-structured } \\
\text { interview }\end{array}$ & Day-to-day practice & \\
\hline $\mathrm{C} 2-\mathrm{C} 4$ & & $\begin{array}{l}\text { Day-to-day practice } \\
+ \\
\text { Formal education }\end{array}$ & $\begin{array}{l}1 \text { semi-structured } \\
\text { interview }\end{array}$ \\
\hline $\mathrm{C} 5-\mathrm{C} 8$ & $\begin{array}{l}1 \text { semi-structured } \\
\text { interview }\end{array}$ & $\begin{array}{l}\text { Day-to-day practice } \\
+ \\
\text { Formal education }\end{array}$ & \\
\hline C9-C16 & $\begin{array}{l}1 \text { semi-structured } \\
\text { interview }\end{array}$ & $\begin{array}{l}\text { Day-to-day practice } \\
+ \\
\text { Formal education }\end{array}$ & $\begin{array}{l}1 \text { semi-structured } \\
\text { interview }\end{array}$ \\
\hline $\mathrm{C} 17$ & & $\begin{array}{l}\text { Day-to-day practice } \\
+ \\
\text { Formal education }\end{array}$ & $\begin{array}{l}2 \text { stimulated recall } \\
\text { interviews }\end{array}$ \\
\hline $\mathrm{C} 18$ & $\begin{array}{l}1 \text { stimulated recall } \\
\text { interview }\end{array}$ & Day-to-day practice & $\begin{array}{l}1 \text { stimulated recall } \\
\text { interview }\end{array}$ \\
\hline C19 & $\begin{array}{l}2 \text { stimulated recall } \\
\text { interviews }\end{array}$ & Day-to-day practice & $\begin{array}{l}2 \text { stimulated recall } \\
\text { interviews }\end{array}$ \\
\hline C20-C21 & $\begin{array}{l}2 \text { stimulated recall } \\
\text { interviews }\end{array}$ & $\begin{array}{l}\text { Day-to-day practice } \\
+ \\
\text { Formal education }\end{array}$ & $\begin{array}{l}2 \text { stimulated recall } \\
\text { interviews }\end{array}$ \\
\hline $\mathrm{C} 22-\mathrm{C} 23$ & $\begin{array}{l}3 \text { stimulated recall } \\
\text { interviews }\end{array}$ & Day-to-day practice & $\begin{array}{l}3 \text { stimulated recall } \\
\text { interviews }\end{array}$ \\
\hline C24-C25 & $\begin{array}{l}3 \text { stimulated recall } \\
\text { interviews }\end{array}$ & $\begin{array}{l}\text { Day-to-day practice } \\
+ \\
\text { Formal education }\end{array}$ & $\begin{array}{l}3 \text { stimulated recall } \\
\text { interviews }\end{array}$ \\
\hline
\end{tabular}




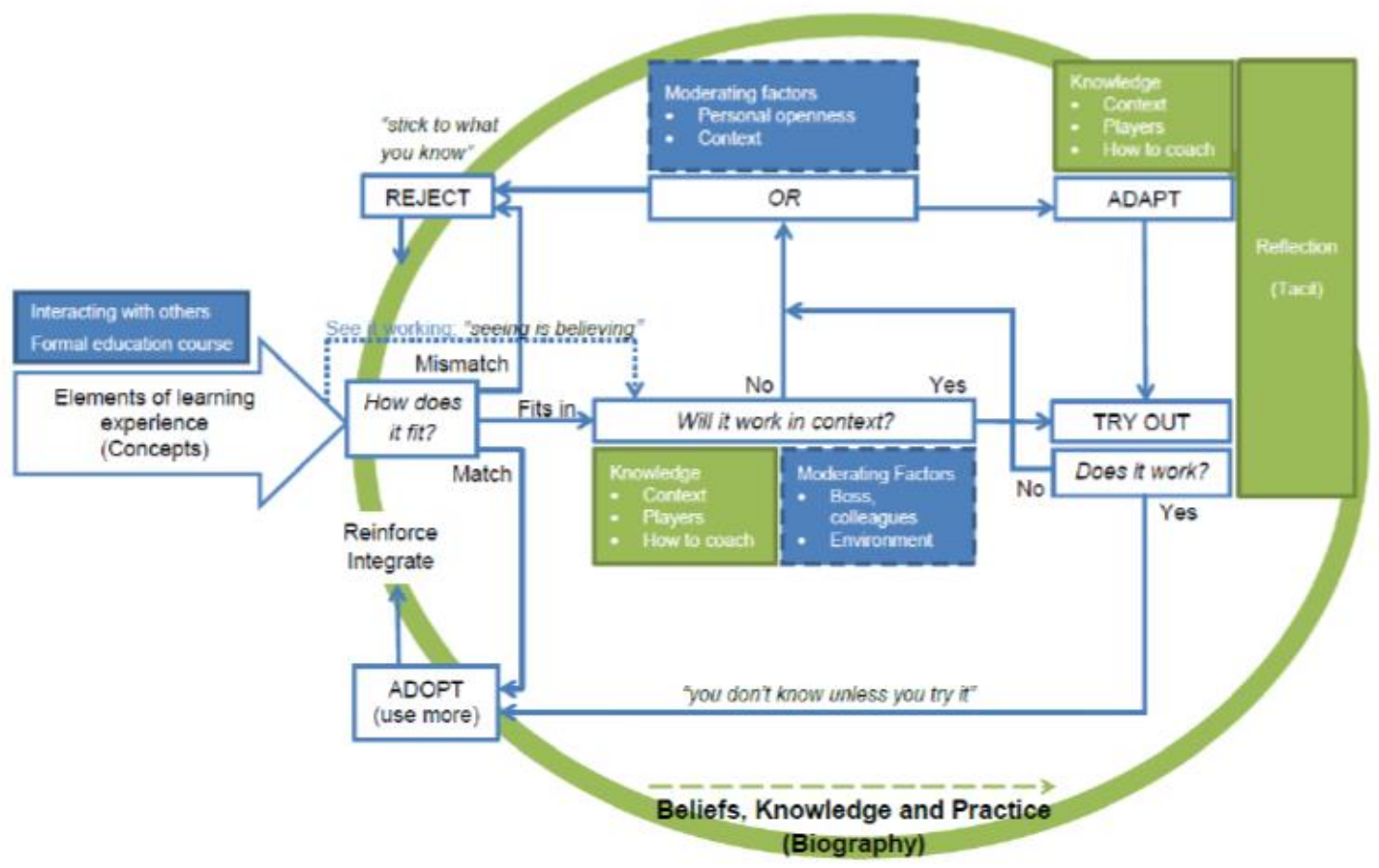

Figure 1. Grounded theory of the learning 'filter' process of soccer coaches (Figure reproduced with permission from Stodter and Cushion 2016, p.41)

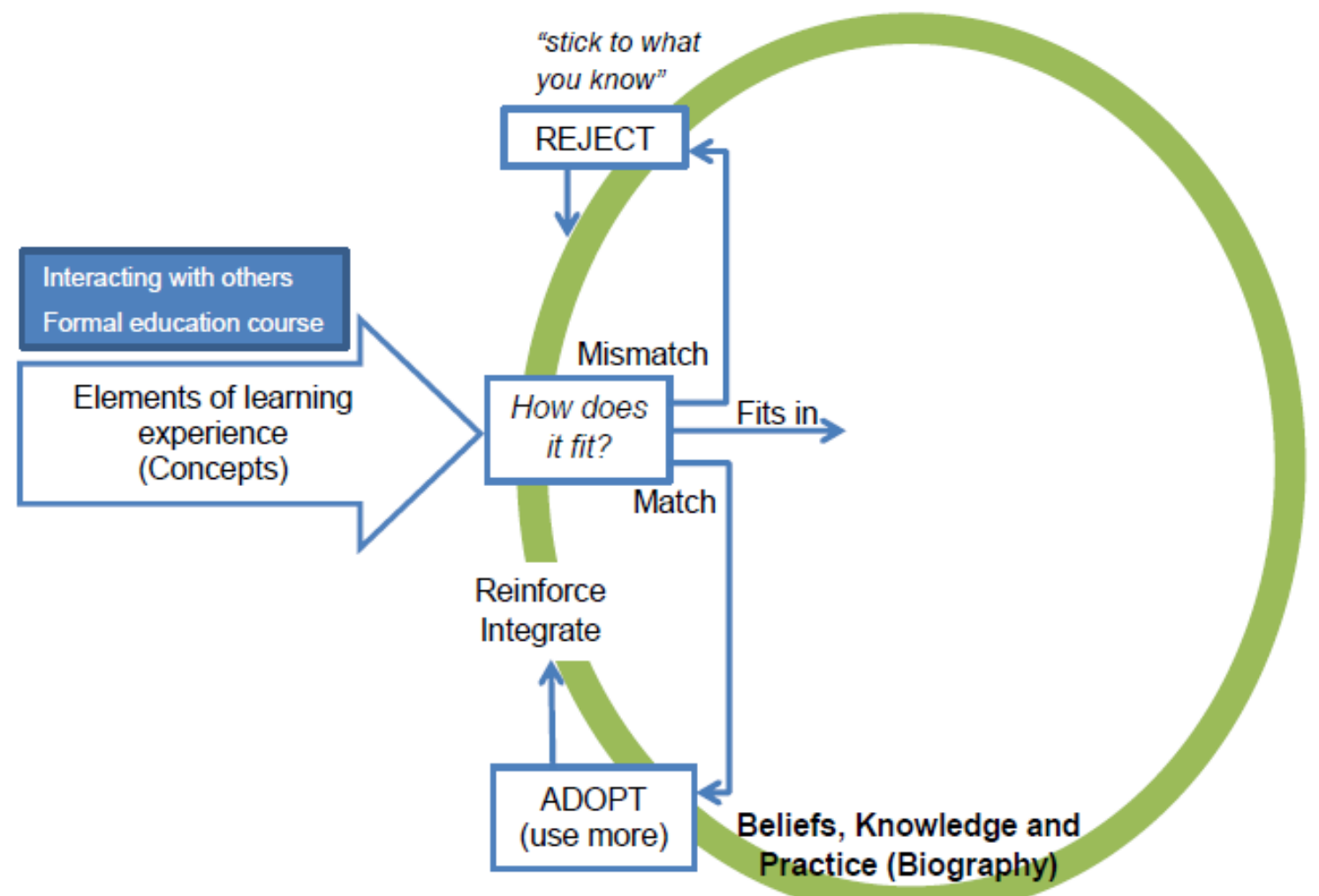

Figure 2. Individual level 'filter' process 


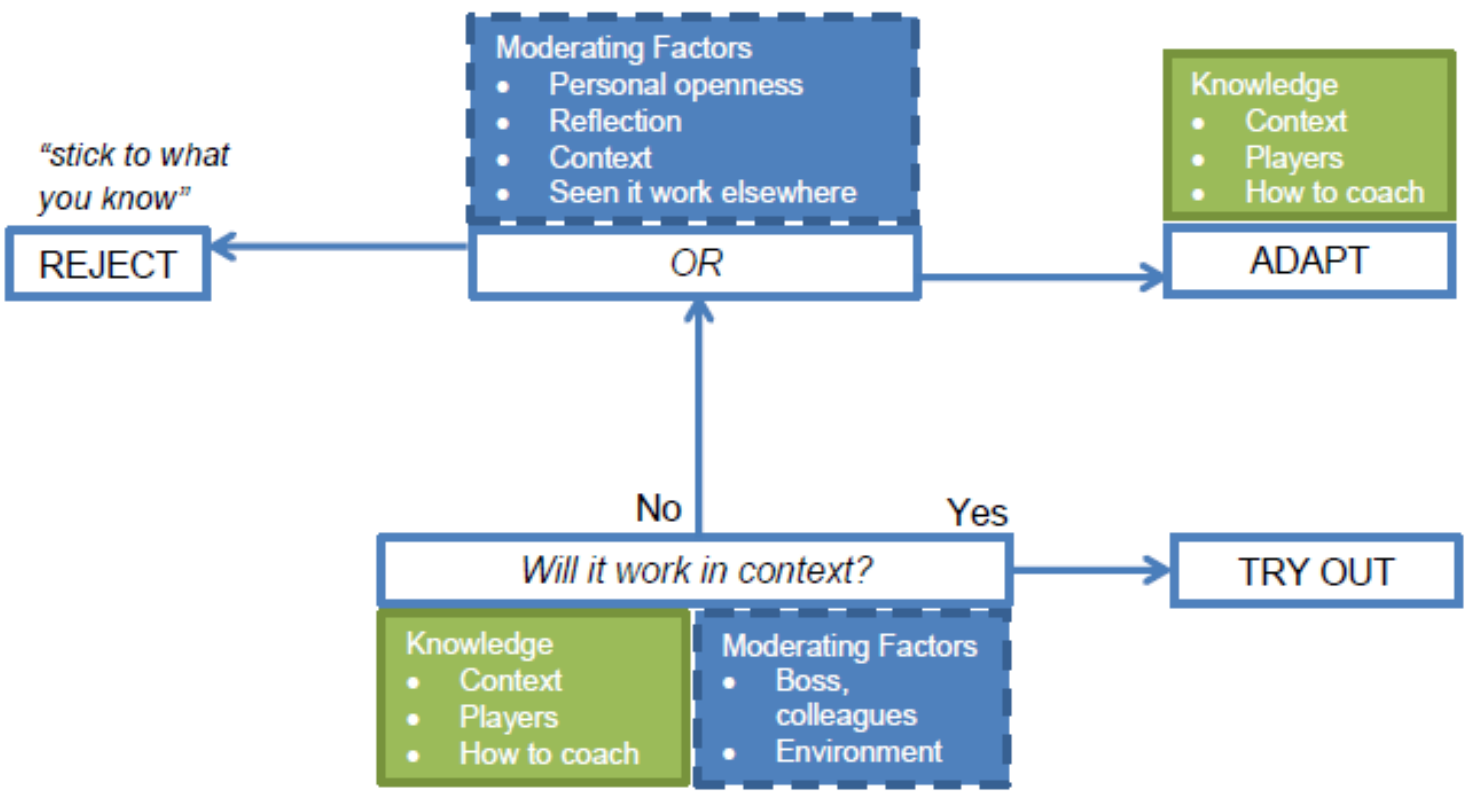

Figure 3. Contextual level 'filter' process

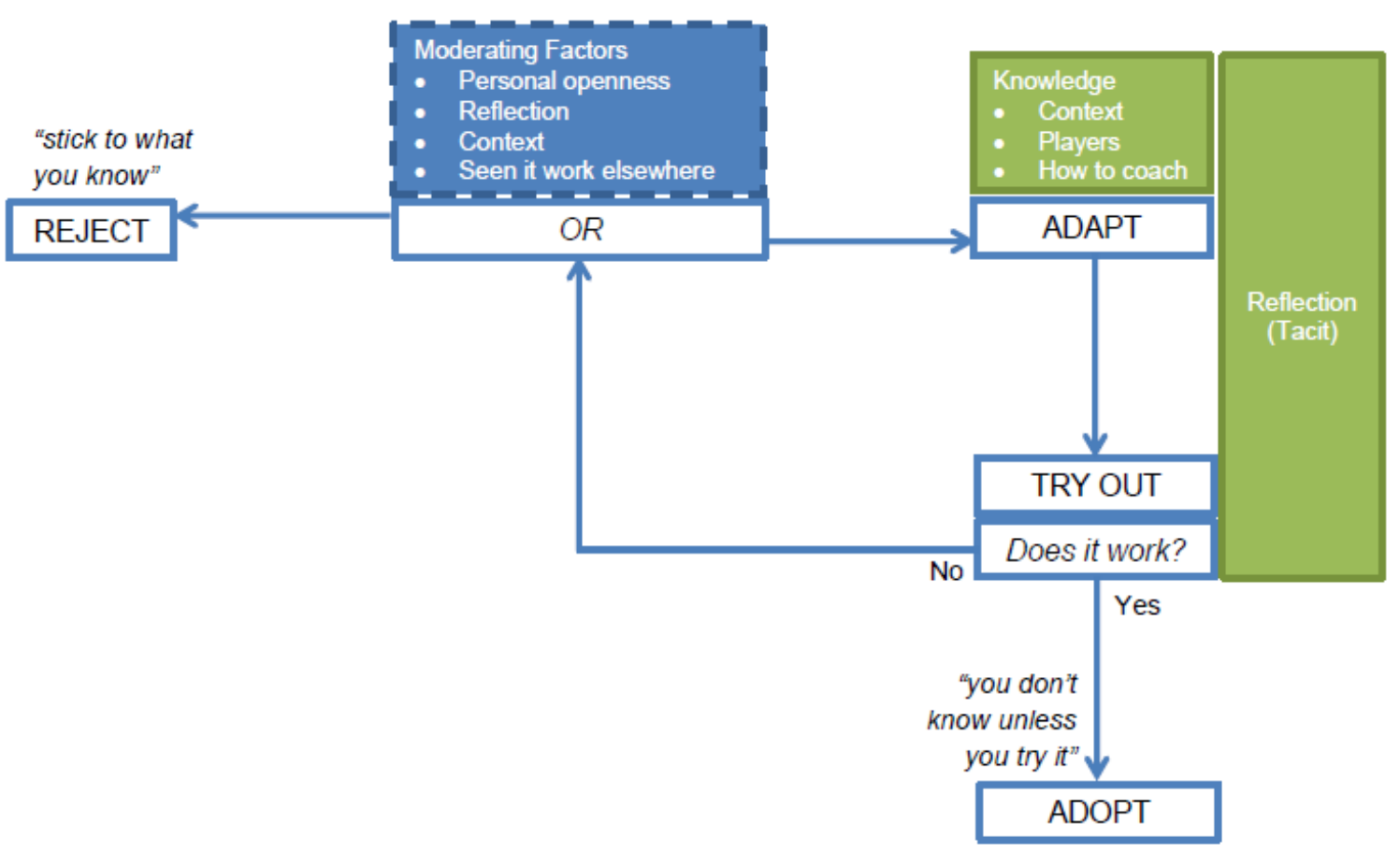

Figure 4. Reflective feedback loop process 


\section{References}

Abraham, A., Collins, D., and Martindale, R., 2006. The coaching schematic: Validation through expert coach consensus. Journal of Sports Sciences, 24, 549-564.

Abraham, A., Collins, D., Morgan, G., and Muir, B., 2009. Developing expert coaches requires expert coach development: Replacing serendipity with orchestration. In A. Lorenzo, S. J. Ibanez and E. Ortega, eds. Aportaciones Teoricas Y Practicas Para El Baloncesto Del Futuro. Sevilla: Wanceulen Editorial Deportiva.

Armour, K.M., 2010. The learning coach...the learning approach: professional development for sports coach professionals. In: J. Lyle and C. Cushion, eds. Sports Coaching: Professionalisation and Practice. China: Elsevier, 153-164.

Armour, K., Quennerstedt, M., Chambers, F., and Makopoulou, K., 2015. What is 'effective' CPD for contemporary physical education teachers? A Deweyan framework. Sport, Education and Society, 1-13.

Armour, K.M., and Yelling, M., 2007. Effective professional development for physical education teachers: the role of informal, collaborative learning. Journal of Teaching in Physical Education, 26, 177-200.

Avalos, B., 2011. Teacher professional development in Teaching and Teacher Education over ten years. Teaching and Teacher Education, 27, 10-20.

Billett, S., 2004. Workplace participatory practices: Conceptualising workplaces as learning environments. Journal of workplace learning, 16(6), 312-324.

Chesterfield, G., Potrac, P., and Jones, R., 2010. 'Studentship' and 'impression management' in an advanced soccer coach education award. Sport, Education and Society, 15(3), 299-314.

Clarke, D., and Hollingsworth, H., 2002. Elaborating a model of teacher professional growth. Teaching and Teacher Education, 18, 947-967.

Coldwell, M., and Simkins, T., 2001. Level models of continuing professional development evaluation: a grounded review and critique. Professional Development in Education, 37(1), 143-157.

Colley, H., 2003. Mentoring for social inclusion: A critical approach to nurturing mentor relationships. London: Routledge. 
Côté, J., Salmela, J., Trudel, P., Baria, A., and Russell, S., 1995. The coaching model: a grounded assessment of expert gymnastic coaches' knowledge. Journal of Sport and Exercise Psychology, 17(1), 1-17.

Cushion, C.J., 2013. Applying Game Centred Approaches in coaching: a critical analysis of the 'dilemmas of practice' impacting change. Sports Coaching Review, 2(1), 61-76.

Cushion, C.J., and Nelson, L., 2013. Coach education and learning: developing the field. In: P. Potrac, W. Gilbert and J. Denison, eds. Routledge Handbook of Sports Coaching. Abingdon: Routledge, 359-374.

Cushion, C.J., Armour, K.M., and Jones, R.L., 2003. Coach education and continuing professional development: Experience and learning to coach. Quest, 55, 215-230.

Day, C. 2002. Developing Teachers: The Challenges of Lifelong Learning. Hoboken: Taylor \& Francis.

Deek, D., Werthner, P., Paquette, K.J., and Culver, D., 2013. Impact of a large-scale coach education program from a lifelong-learning perspective. Journal of Coaching Education, 6(1), 23-42.

Duffy, P., Hartley, H., Bales, J., Crespo, M, Dick, F., Vardhan, D., Nordman, L. and Curado, J., 2011. Sport coaching as a 'profession': challenges and future directions. International Journal of Coaching Science, 5(2), 93-123

Eisner, E.W. 1985. The educational imagination: On the design and evaluation of school programs $2^{\text {nd }}$ ed. New York: Macmillan.

Entwistle, N.J., and Peterson, E.R., 2004. Conceptions of learning and knowledge in higher education: relationships with study behavior and influences of learning environments. International Journal of Educational Research, 41, 407-428.

Entwistle, N., Skinner, D., Entwistle, D., and Orr, S., 2000. Conceptions and beliefs about 'good teaching': an integration of contrasting research areas. Higher Education Research and Development, 19(1), 5-26.

Goodall, J., Day, C., Lindsay, G., Muijs, D., and Harris, A., 2005. Evaluating the Impact of CPD (Research Report No. 659). Department for Education and Skills, London.

Eraut, M., 2000. Non-formal learning and tacit knowledge in professional work. British Journal of Educational Psychology, 70, 113-136. 
Erickson, K., Côté, J. \& Fraser-Thomas, J. 2007 Sport experiences, milestones and educational activities associated with high-performance coaches' development, The Sport Psychologist, 21, 302-316.

Gilbert, W., and Trudel, P., 2001. Learning to coach through experience: Reflection in model youth sport coaches. Journal of Teaching in Physical Education, 21, 16-34.

Griffiths, M.A., and Armour, K.M., 2013. Volunteer sport coaches and their learning dispositions in coach education. International Journal of Sports Science and Coaching, 8(4), 677-688.

Griffiths, M.A., Armour, K., \& Cushion, C., 2016. 'Trying to get our message across': Successes and challenges in an evidence-based professional development programme for sport coaches. Sport, Education and Society. DOI:

$10.1080 / 13573322.2016 .1182014$

Groom, R., Cushion, C., and Nelson, L., 2011. The delivery of video-based performance analysis by England youth soccer coaches: towards a grounded theory. Journal of Applied Sport Psychology, 23(1), 16-32.

Guskey, T.R., 2002. Does it make a difference? Evaluating professional development. Educational Leadership, 59(6), 45-51.

Hager, P., \& Hodkinson, P. 2009. Moving beyond the metaphor of transfer of learning. British Educational Research Journal, 35(4), 619-638.

Harland, J., and Kinder, K., 1997. Teachers' continuing professional development: framing a model of outcomes. British Journal of In-service Education, 23(1), 71-84.

Holt, N.L., Knight, C.J., and Tamminen, K.A., 2012. Grounded theory. In: K. Armour and D. Macdonald, eds. Research methods in physical education and youth sport. Routledge: Abingdon, 277-294.

Jarvis, P., 2006. Towards a comprehensive theory of human learning. London: Routledge.

Jarvis, P., 2009. Learning to be a person in society. London: Routledge.

Jones, K., 2015. Foreword. Professional Development in Education, 41(2), 159-160.

Jones, R.L., 2006. The Sports Coach as Educator: Reconceptualising Sports Coaching. Abingdon: Routledge.

Jones, R.L., Edwards, C., and Viotto Filho, I.A.T., 2014. Activity theory, complexity and 
sports coaching: an epistemology for a discipline. Sport, Education and Society, DOI: 10.1080/13573322.2014.895713.

Kemmis, S., 2010. Research for praxis: Knowing doing. Pedagogy, Culture \& Society, 18(1), 9-27.

Kennedy, A., 2014. Understanding continuing professional development: the need for theory to impact on policy and practice. Professional Development in Education, 40(5), 688697.

Kolb, D.A., 1984. Experiential learning: experience as the source of learning and development. Prentice Hall: Englewood Cliffs.

Knowles, M., 1980. The modern practice of adult education: Andragogy versus Pedagogy. Chicago: Follett.

Leduc, M., Culver, D.M., and Werthner, P., 2012. Following a coach education programme: coaches’ perceptions and reported actions. Sports Coaching Review, 1(2), 135-150.

Lemyre, F., Trudel, P. \& Durand-Bush, N. 2007. How youth-sport coaches learn to coach, The Sport Psychologist, 21, 191-209.

Light, R., and Robert, J.E., 2010. The impact of game sense pedagogy on Australian rugby coaches' practice: a question of pedagogy. Physical Education and Sport Pedagogy, 15(2), 103-115.

Lyle, J., 2003. Stimulated recall: a report on its use in naturalistic research. British Educational Research Journal, 29(6), 861-878

Lyle, J., 2007. UKCC Impact Study: Definitional, Conceptual and Methodological Review. Leeds: National Coaching Foundation

McCullick, B.A., Schempp, P., Mason, I., Foo, C., Vickers, B., and Connolly, G., 2009. A scrutiny of the coaching education program scholarship since 1995. Quest, 61, 322335.

McLaughlin, M.W., and Zarrow, J., 2001. Teachers engaged in evidence-based reform: Trajectories of teacher's inquiry, analysis and action. In: A. Lieberman and L. Miller, eds. Teachers Caught in the Action. Professional Development that Matters. New York, Teachers College, 79-101. 
Mezirow, J., 2009. An overview on transformative learning. In: K. Illeris, ed. Contemporary Theories of Learning. Abingdon: Routledge, 90-105.

Moon, J., 2001. Short courses and modules: improving the impact of learning, training and professional development. London: Kogan Page.

Moon, J., 2004. A handbook of reflective and experiential learning - theory and practice. London: RoutledgeFalmer.

Neimeyer, G. J., Taylor, J. M., and Cox, D. R., 2012. On hope and possibility: Does continuing professional development contribute to ongoing professional competence? Professional Psychology: Research and Practice, 43(5), 476.

Nelson, L., Cushion, C.J., and Potrac, P., 2006. Formal, nonformal and informal coach learning: a holistic conceptualisation. International Journal of Sports Science and Coaching, 1(3), 247-259.

Nelson, L., Cushion, C., and Potrac, P., 2012. Enhancing the provision of coach education: the recommendations of UK coaching practitioners. Physical Education and Sport Pedagogy, DOI:10.1080/17408989.2011.649725.

Opfer, V. D., \& Pedder, D. 2011. Conceptualizing Teacher Professional Learning. Review of Educational Research, 81(3), 376-407. DOI:10.3102/0034654311413609.

Partington, M., and Cushion, C.J., 2013. An investigation of the practice activities and coaching behaviours of professional top-level youth soccer coaches. Scandinavian Journal of Medicine and Science in Sports, 23(3), 373-382.

Partington, M., and Cushion, C.J. 2012. Performance during performance: using Goffman to understand the behaviours of elite youth football coaches during games. Sports Coaching Review, 1(2), 93-105.

Patton, M.Q., 2002. Qualitative research and evaluation methods. Thousand Oaks: Sage.

Piggott, D., 2012. Coaches' experiences of formal coach education: a critical sociological investigation. Sport, Education and Society, 17(4), 535-554.

Piggott, D., 2013. The Open Society and coach education: a philosophical agenda for policy reform and future sociological research. Physical Education and Sport Pedagogy. DOI: $10.1080 / 17408383.2013 .837435$.

Postholm, M.B., 2012. Teachers' professional development: a theoretical review. 
Educational Research, 54(4), 405-429.

Saury, J. and Durand, M., 1998. Practical knowledge in expert coaches: On-site study of coaching in sailing. Research Quarterly for Exercise and Sport, 69, 254-266.

Schempp, P.G., and Graber, K.C. 1992. Teacher socialization from a dialectical perspective: pretraining through induction. Journal of Teaching in Physical Education, 11, 329348.

Schempp, P.G., Webster, C., McCullick, B.A., Busch, C., C. \& Sannen Mason, I. 2007 How the best get better: an analysis of the self-monitoring strategies used by expert golf instructors, Sport, Education and Society, 12(2), 175-192.

Schön, D.A., 1983. The reflective practitioner: how professionals think in action. Farnham: Ashgate.

Schön, D.A., 1987. Educating the reflective practitioner. San Francisco: Jossey-Bass.

Sports coach UK, 2015. What is the UKCC? [online]. Available from: http://www.sportscoachuk.org/resource/what-ukcc [accessed 10th Aug 2015].

Strauss, A., and Corbin, J., 1998. Basic of qualitative research: Techniques and procedure for developing grounded theory. 2nd ed. Thousand Oaks: CA.

Stodter, A., and Cushion, C.J., 2014. Coaches' learning and education: a case study of cultures in conflict. Sports Coaching Review, 3(1), 63-79.

Stodter, A., and Cushion, C.J., 2016. Effective coach learning and the processes of coaches' knowledge development: what works? In: P.A Davis, ed. The Psychology of Effective Coaching and Management. Nova Science Publishers, 35-52.

Stoszkowski, J., and Collins, D., 2015. Sources, topics and use of knowledge by coaches. Journal of Sports Sciences, DOI:10.1080/02640414.2015.1072279.

Taylor, W.G., and Garratt, D., 2013. Coaching and professionalisation. In: P. Potrac, W. Gilbert and J. Denison, (eds.) Routledge Handbook of Sports Coaching. Abingdon: Routledge, 27-39.

Thompson, A., Potrac, P., and Jones, R., 2013. 'I found out the hard way': micro-political workings in professional football. Sport, Education and Society, DOI: 10.1080/13573322.2013.862786.

Trudel, P., Culver, D., and Werthner, P., 2013. Looking at coach development from the 
coach-learner's perspective: considerations for coach administrators. In: P.Potrac, W. Gilbert and J. Denison, eds. Routledge handbook of sports coaching. Abingdon: Routledge, 375-387.

Trudel, P., Gilbert, W., and Werthner, P., 2010. Coach education effectiveness. In: Lyle, J. and Cushion, C., eds. Sports coaching: Professionalisation and practice. China: Elsevier, 135-152.

Tusting, K., and Barton, D., 2003. Models of Adult Learning: A Literature Review. London: NRDC.

Vygotsky, L.S., 1978. Mind and society. Cambridge, MA: MIT Press.

Werthner, P., and Trudel, P., 2009. Investigating the idiosyncratic learning paths of elite Canadian Coaches. International Journal of Sports Science and Coaching, 4, 433449.

WestEd, 2000. Teachers Who Learn, Kids Who Achieve. San Francisco: WestEd.

Wright, T., Trudel, P. \& Culver, D. 2007. Learning how to coach: the different learning situations reported by youth ice hockey coaches, Physical Education and Sport Pedagogy, 12(2), 127-144. 